\title{
DeleVERAGING CAPM: ASSET BETAS VS. EQUITY BETAS
}

\author{
GAIA BARONE
}




\section{CONTENTS}

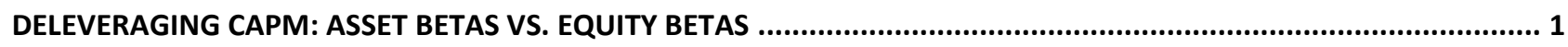

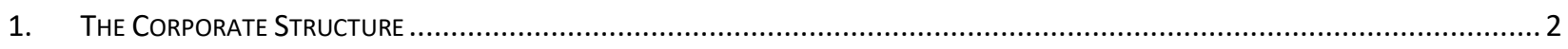

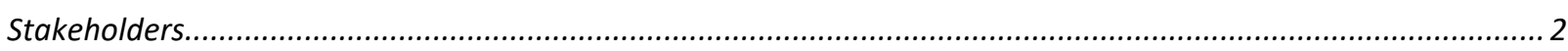

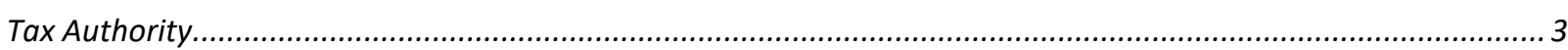

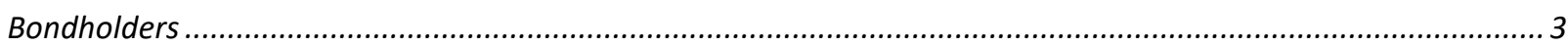

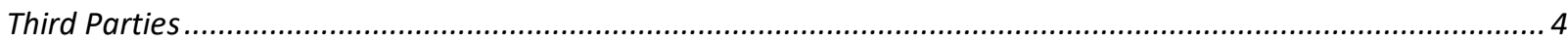

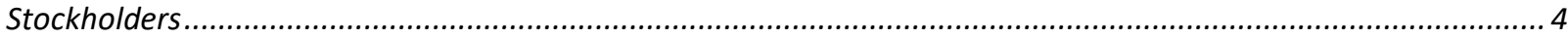

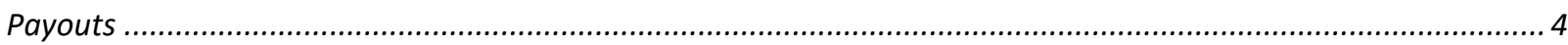

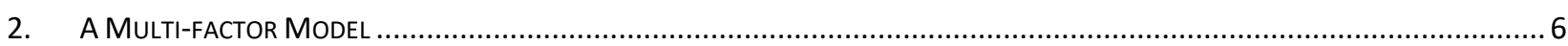

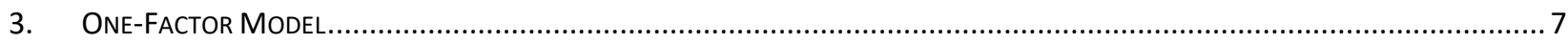

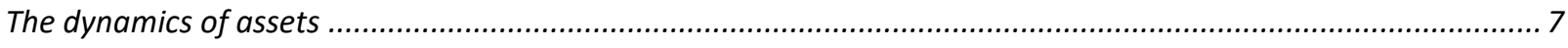

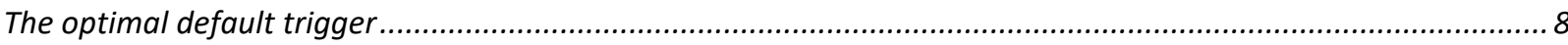

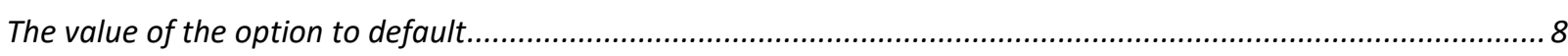

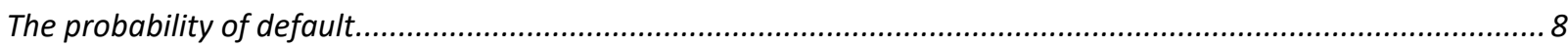

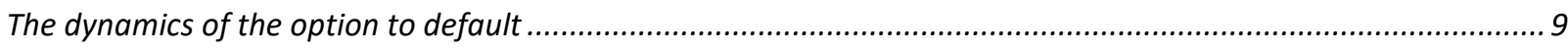

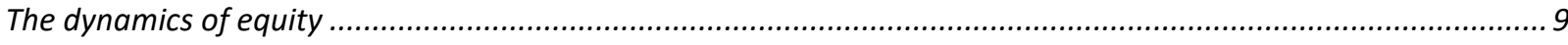

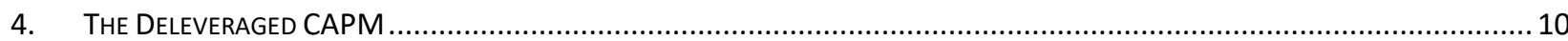

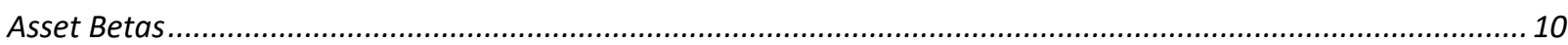

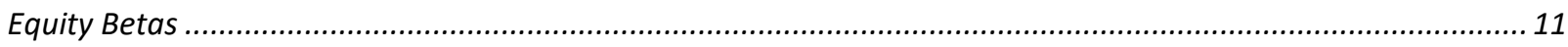

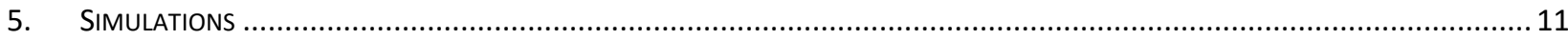

Asset Returns vs. Equity Returns: Density Functions .................................................................................. 11

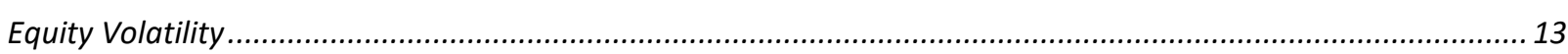

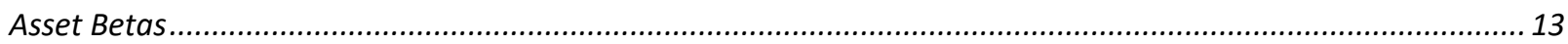

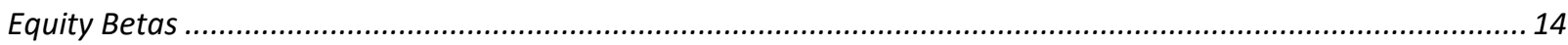

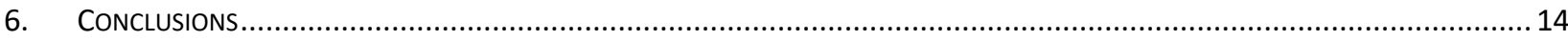

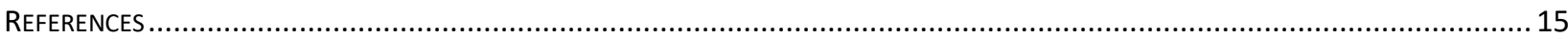

Gaia Barone

docenti.luiss.it/gbarone 


\section{Deleveraging CAPM:}

\section{Asset Betas vs. Equity Betas}

\section{Gaia Barone}

GAIA BARONE

Advanced Financial Mathematics LUISS - Guido Carli University of Rome gbarone@luiss.it
The classic estimates of CAPM equity betas are notoriously unstable. We suppose that this is mainly due to changes of firm's leverage over time.

In order to take leverage into account, we propose a new approach where asset correlations among firms are pairwise constant, while equity correlations depend on the stochastic evolution of firms' asset values.

$\mathrm{T}$

he classic Capital Asset Pricing Model (CAPM) paved the way to a huge literature in asset pricing. The most prominent yardstick is the arbitrage pricing theory (APT), by Stephen Ross ([13]), that is now widely applied in asset management. ${ }^{1}$

As stated by Mark Rubinstein ([14], p. 273), "While the assumptions of the [APT] model are more general than the CAPM (not requiring assumptions about investor preferences and very weak assumptions on probability distributions), at the same time the conclusions are much less specific since the number of factors and the factors themselves are not identified."

In APT's empirical tests where factors have been specified a priori, macroeconomic variables such as expected inflation or output have been selected to capture the systematic risk in the economy. Instead, our approach focuses on firm-specific variables, even if it allows for market-wide factors. We concentrate the analysis on the effects of capital structure on investment decisions, in order to highlight the impact of leverage, taxes and bankruptcy costs on the value of corporate securities.

Similarly to APT and CAPM (that can be viewed as nested within the APT), our "perpetual debt structural model" (PDSM) assumes a linear relationships between returns and marketwide factors. However, our linearity-assumption concerns the returns on firm's assets, not those on equity. We assume that the return on assets follows a Geometric Brownian Motion, where the drift rate is constant and asset returns are stably normal. On the other hand, the return on equity is only locally normal: Its drift changes as a function of assets' value and time, consistently with a huge empirical literature on non-normality of equity returns. ${ }^{2}$

Therefore, our settings is similar to CAPM, but at a lower layer: Instead of assuming a linear relationships between equity returns and market factors, we assume a linear relationships between assets' returns and market factors. In our model, as a consequence of leverage, the relationship between equity returns and market factors is strongly non-linear.

1 Currently a hot topic among investors ([11]) is "smart beta", a concept that can be tracked back to APT. However, smart betas made Bill Sharpe "definitionally sick" ([1]). In our approach, a better expression for the same concept is given by the term "asset beta".

2 For a short review of the first tests, see Granger and Morgenstern ([7], Section 7.2, pp. 179-82). 
TABLE 1 Contracts between stakeholders.

\begin{tabular}{|c|c|c|c|c|}
\hline \multirow{2}{*}{ Contracts } & \multicolumn{4}{|c|}{ Stakeholders } \\
\hline & Stockholders & Bondholders & Third parties & Tax Authority \\
\hline Firm's assets & $V_{0}$ & - & - & - \\
\hline Risk-free bond & $-Z$ & $Z$ & - & - \\
\hline Option to default & $P_{0} \equiv\left(Z-V_{b}\right) p_{b}$ & $-P_{0} \equiv-\left(Z-V_{b}\right) p_{b}$ & - & - \\
\hline Bankruptcy security & - & $-A_{0} \equiv-\alpha V_{b} p_{b}$ & $A_{0} \equiv \alpha V_{b} p_{b}$ & - \\
\hline Tax claims & $-G_{S} \equiv-\vartheta\left(V_{0}-Z+P_{0}\right)$ & $-G_{B}=-\vartheta\left(Z-P_{0}-A_{0}\right)$ & $-G_{U} \equiv-\vartheta A_{0}$ & $G_{0} \equiv G_{S}+G_{B}+G_{U}$ \\
\hline Tota & $S_{0} \equiv(1-\vartheta)\left(V_{0}-Z+P_{0}\right)$ & $B_{0} \equiv(1-\vartheta)\left(Z-P_{0}-A_{0}\right)$ & $U_{0} \equiv(1-\vartheta) A_{0}$ & $G_{0} \equiv \vartheta V_{0}$ \\
\hline
\end{tabular}

Note: $p_{b}$ is the value of a perpetual first-touch digital option which pays 1 when $V=V_{b}$ at default time $\tau$.

The scheme of this paper is as follows: After describing the corporate structure of an idealized firm ( $(1)$, we present our assumptions about the dynamics of the firm's assets in a multi-factor environment ( $\$ 2)$. Next (\$3) we introduce the one-factor version of the model. Finally we show (\$4) the formulas of asset and equity returns and (\$5) some simulations of our "deleveraged CAPM". Our final considerations (\$6) close the paper.

\section{THE CORPORATE STRUCTURE}

The corporate structure is very simple, but it is capable to synthetize the interrelationships among the main actors during the life of the firm and at the time of default (Table 1).

\section{Stakeholders}

The claimants of firm's assets are stockholders, bondholders, third parties (lawyers, accountants, courts, etc.) and the Tax Authority. Our basic balance-sheet relationship, at time 0 , is

$$
V_{0}=B_{0}+U_{0}+G_{0}+S_{0}
$$

where

$V_{0}$ is the current value of assets;

$B_{0}$ is the current value of bonds;

$U_{0}$ is the current value of third-parties' claims;

$G_{0}$ is the current value of the Tax Authority's claim;

$S_{0}$ is the current value of equity.

The firm's basic structure is similar to the one proposed by Leland ([12]). ${ }^{3}$ The critical differences with respect to the Leland's model are due to our different assumptions about the tax structure. They have been highlighted in a previous article ([2], pp. 12-3). In particular, according to our model, the value of equity is an inverse function of the tax rate: if the tax rate increases, the value of equity decreases (as it should be expected).

3 The Leland model's prominent role among structural models is witnessed by its receiving the first Stephen A. Ross Prize in Financial Economics from the Foundation for the Advancement of Research in Financial Economics - FARFE ([6]). 


\section{Tax Authority}

We assume that the Tax Authority has the right to receive the share $\vartheta$ of the firm's earnings, where $\vartheta$ is the tax rate. ${ }^{4}$

Therefore, the current value of the Tax Authority's claim, $G_{0}$, is

$$
G_{0}=\vartheta V_{0} .
$$

In other terms, the Tax Authority can be considered as a "special partner" of stockholders, because it claims a share $\vartheta$ of the firm's assets as soon as the firm is created.

When the bonds are issued, the tax burden $G_{0}$ is redistributed among the firm's claimants, to include the newcomers (bondholders and third parties). Therefore

$$
G_{0}=G_{B}+G_{U}+G_{S}
$$

where $G_{B}, G_{U}$ and $G_{S}$ are the current values of the taxes levied on bondholders, third parties and stockholders, respectively.

\section{Bondholders}

In our structural framework, the bondholders buy from the stockholders a perpetual bond with nominal value $Z$ and coupon $C=r Z$, where $r$ is the risk-free interest rate.

The (after-tax) current value of the perpetual bond, $B_{0}$, is

$$
B_{0}=(1-\vartheta)\left(Z-P_{0}-A_{0}\right)
$$

where

$P_{0}$ is the (before-tax) current value of the "option to default" sold by bondholders to stockholders;

$A_{0}$ is the (before-tax) current value of the so-called "bankruptcy security", given for free by bondholders to third parties.

\section{Option to Default}

The bondholders sell to stockholders an option to default, more precisely a perpetual American put option, with strike $Z$ and (before-tax) market value $P_{0}$, written on $V$.

When the value of the firm's assets falls, the value of the stockholders' put option rises. At some (sufficiently low) point, $v_{b}$, the stockholders exercise their option to default in order to prevent equity's value to become negative. The optimal default trigger, $V_{b}$, is endogenous. It is determined by stockholders by maximizing the current value of equity.

When the stockholders exercise their put option, they receive $Z$ from the bondholders in exchange for the firm's assets, whose value is $V_{b}$. Therefore, at time $\tau(0<\tau \leq+\infty)$, when the company files for bankruptcy protection, the (before-tax) exercise value of the option to default is

$$
P_{\tau}=Z-V_{b}
$$

\footnotetext{
4 In the notation used by Goldstein-Ju-Leland (2001), interest payments to investors are taxed at a personal rate $\tau_{i}$, "effective" dividends are taxed at $\tau_{d}$, and corporate profits are taxed at $\tau_{c}$. We assume

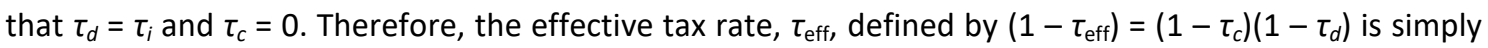
equal to $\tau_{d}=\tau_{i}$ (and to $\vartheta$, in our notation).
} 


\section{Third Parties}

When the company defaults, the third parties (lawyers, accountants, courts, etc.) claim a share $\alpha$ of the firm's assets, whose value at default is $V_{b}$. Therefore, the bankruptcy triggers the execution of the above-cited bankruptcy security. Its (after-tax) current value, $U_{0}$, is

$$
U_{0}=(1-\vartheta) A_{0} \text {. }
$$

\section{Bankruptcy Security}

The bankruptcy security "comes to light" at the time of default, $\tau$, but has been given for free from bondholders to third parties as soon as the perpetual bond is issued.

Actually, the bankruptcy security is a perpetual digital option, with barrier $V_{b}$, that offers to third parties a rebate equal to $\alpha V_{b}$ at $\tau(0<\alpha<1)$.

\section{Stockholders}

In our model, the firm's equity is a portfolio whose (after-tax) current value, $S_{0}$, is given by

$$
S_{0}=(1-\vartheta)\left(V_{0}-Z+P_{0}\right)
$$

In other terms, the current value of the stockholders' (before-tax) claim, $V_{0}-Z+P_{0}$, is equal to the value of a portfolio that is short on the debt's nominal value, $Z$, and is long on the firm's assets, $V_{0}$, and on the option to default, $P_{0}$.

\section{Leverage}

The current leverage, $L_{0}$, is defined as the ratio between the after-tax value of assets, $(1-\vartheta) V_{0}$, and the value of equity, $S_{0}$ :

$$
L_{0} \equiv \frac{(1-\vartheta) V_{0}}{S_{0}}=\frac{V_{0}}{V_{0}-Z+P_{0}}
$$

In particular, $L_{0}=1$ for a full-equity firm, where $Z=P_{0}=0$. Besides, in the case of a non-fullequity firm, $L_{\tau}=+\infty$ at default, when $V_{\tau}=V_{b}$ and $P_{\tau}=Z-V_{b}$.

\section{Payouts}

The firm can liquidate assets to make interest, dividend and tax payments. The payout policy is "tax-neutral", so that the Tax Authority is neither worst-off nor better-off after a payout equal to $q_{V} V$, were $q_{V}$ is the payout rate per unit of time. Any payout is taxed at the tax rate $\vartheta$.

By assuming a tax-neutral payout policy, the (overall) payout, $q_{V} V_{0}$, is equal to the sum of gross interests, $q_{B}\left(Z-P_{0}-A_{0}\right)$, and gross dividends, $q_{s}\left(V_{0}-Z+P_{0}\right)$,

$$
q_{V} V_{0}=q_{B}\left(Z-P_{0}-A_{0}\right)+q_{s}\left(V_{0}-Z+P_{0}\right)
$$

where $q_{B}$ is the (before-tax) bond yield and $q_{S}$ is the (before-tax) dividend yield.

Similarly, the (after-tax) payout, $(1-\vartheta) q_{V} V_{0}$, is equal to the sum of net interests, (1७) $q_{B}\left(Z-P_{0}-A_{0}\right)$, and net dividends, $(1-\vartheta) q_{s}\left(V_{0}-Z+P_{0}\right)$,

$$
(1-\vartheta) q_{V} V_{0}=(1-\vartheta) q_{B}\left(Z-P_{0}-A_{0}\right)+(1-\vartheta) q_{s}\left(V_{0}-Z+P_{0}\right)
$$

Therefore, the (overall) payout, $q_{v} V_{0}$, can be written as the sum of net interests, net dividends, and taxes, $\vartheta q_{V} v_{0}$ :

$$
q_{V} V_{0}=(1-\vartheta) q_{B}\left(Z-P_{0}-A_{0}\right)+(1-\vartheta) q_{S}\left(V_{0}-Z+P_{0}\right)+\vartheta q_{V} V
$$




\section{Bond Yield}

As stated earlier, the perpetual bond pays a coupon $C=r Z$. Therefore, gross interests, $q_{B}(Z-$ $\left.P_{0}-A_{0}\right)$, are equal to $r Z$

$$
q_{B}\left(Z-P_{0}-A_{0}\right)=r Z
$$

and the (before-tax) bond yield, $q_{B}$, is equal to

$$
q_{B}=\frac{r Z}{Z-P_{0}-A_{0}} .
$$

In particular, if the default probability is null, then the value of the option to default, $P_{0}$, and the value of the bankruptcy security, $A_{0}$, are both null. Therefore, the bond yield, $q_{B}$, is equal to $r$. At default, when $A_{\tau}=\alpha V_{b}$ and $P_{\tau}=Z-V_{b}$, the bond yield is equal to

$$
q_{B}=\frac{r Z}{(1-\alpha) V_{b}} .
$$

\section{Credit Spread}

By (13), the bond's credit spread, $s_{B}$, is given by

$$
s_{B} \equiv q_{B}-r=\frac{r\left(P_{0}+A_{0}\right)}{Z-P_{0}-A_{0}} .
$$

\section{Dividend Yield}

Finally, note that by substituting (12) in (9), gross dividends, $q_{s}\left(V_{0}-Z+P_{0}\right)$, are equal to

$$
q_{s}\left(V_{0}-Z+P_{0}\right)=q_{V} V_{0}-r Z
$$

Therefore, the (before-tax) dividend yield, $q_{s}$, is equal to

$$
q_{S}=\frac{q_{V} V_{0}-r Z}{V_{0}-Z+P_{0}}
$$

The payout rate, $q_{v}$, determines the cash flow $q_{v} v_{0}$ which is taken out of the assets of the firm. What is left out of this cash flow (after paying interest on debt) is paid out to shareholders as dividends.

If $q_{V} V_{0}$ is insufficient to cover coupons on the bond, shareholders receive a negative dividend (i.e., contribute additional cash to the firm). A negative dividend (a cash-flow crisis) does not mean that that it is optimal to default: Expected future cash flows could be sufficiently high to induce stockholders to keep the firm alive.

In order to highlight the role of leverage, $L$, let's substitute (8) in (17). Then the (before-tax) dividend yield, $q_{s}$, can be written as

$$
q_{s}=\left(q_{v}-\frac{r Z}{V_{0}}\right) L .
$$

In the case of a full-equity firm, where $Z=0$ and $L_{0}=1, q_{s}=q_{v}$. 


\section{A MULTI-FACTOR MODEL}

We assume that the "anchor" of the economic system is given by a risk-free perpetual bond (or money-market account), with current value $H_{0} \equiv 1$, that continuously offers a constant riskfree interest rate, $r$ :

$$
\frac{d H}{H}=r d t
$$

The evolution of the firms' asset values, $V_{i}(i=1, \ldots, n)$, is governed by a multi-dimensional geometric Brownian motion:

$$
\frac{d V_{i}}{V_{i}}=\left(\mu_{V_{i}}-q_{V_{i}}\right) d t+\sum_{k=1}^{m} \beta_{i k} \sigma_{k} d F_{k}+u_{i} d \omega_{i}
$$

where

$\mu_{v_{i}}$ is the instantaneous expected rate of return on the $i$-th firm per unit time;

$$
\mu_{v_{i}}=r+\sum_{k=1}^{m} \beta_{i k} \lambda_{k}
$$

and $\lambda_{k}$ is the (non-necessarily constant) market price of the $k$-th factor risk $(k=1,2, \ldots, m)$;

$q_{v_{i}}$ is the payout rate of the $i$-th firm per unit time;

$\boldsymbol{B}_{i k}$ is the $i$-th firm's asset beta (i.e. loading) with respect to the $k$-th factor;

$\sigma_{k}$ is the volatility of the $k$-th factor, whose current value is $F_{k}$;

$d F_{k}$ is the Wiener process of an orthogonal and normalized factor

$$
\begin{gathered}
d F_{k}=\varepsilon_{k} \sqrt{d t}, \quad E\left(\varepsilon_{k}\right)=0 \text { and } E\left[\left(\varepsilon_{k}\right)^{2}\right]=1 \\
E\left(d F_{k}\right)=E\left(\varepsilon_{k}\right) \sqrt{d t}=0, \quad E\left[\left(d F_{k}\right)^{2}\right]=E\left[\left(\varepsilon_{k}\right)^{2}\right] d t=d t \quad \text { and } E\left(d F_{k}, d F_{l}\right)=0 \text { for } k \neq 1
\end{gathered}
$$

and $\varepsilon_{k}$ is a standardized normal random variable with null mean and unit variance;

$u_{i}$ is the volatility of the $i$-th firm's idiosyncratic residual;

$d \omega_{i}$ is a Wiener process, with

$$
\begin{gathered}
d \omega_{i}=\varepsilon_{i} \sqrt{d t}, \quad E\left(\varepsilon_{i}\right)=0 \text { and } E\left[\left(\varepsilon_{i}\right)^{2}\right]=1 \\
E\left(d \omega_{i}\right)=E\left(\varepsilon_{i}\right) \sqrt{d t}=0, \quad E\left[\left(d \omega_{i}\right)^{2}\right]=E\left[\left(\varepsilon_{i}\right)^{2}\right] d t=d t \quad \text { and } E\left(d \omega_{i}, d \omega_{j}\right)=0 \text { for } i \neq j
\end{gathered}
$$

and $\varepsilon_{i}$ is a standardized normal random variable with null mean and unit variance.

Besides factors and residuals are orthogonal:

$$
E\left(d \omega_{i}, d F_{k}\right)=0 \quad \text { for } i=1,2, \ldots, n \text { and } k=1,2, \ldots, m
$$

The vector of expected total returns on assets and the variance-covariance matrix are

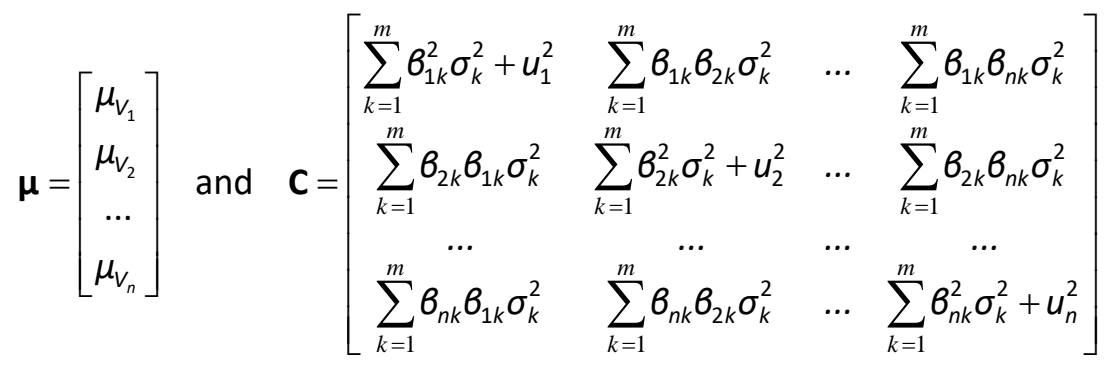




\section{ONE-FACTOR MODEL}

In the one-factor version of the model, we assume - consistently with the standard version of CAPM - that firms face only one pervasive market-wide factor, $F$, with drift rate $\mu_{F}$ and variance rate $\sigma_{F}^{2}$.

The dynamics of assets

If $d M$ is the standardized rate of return on the "market portfolio"

$$
d M \equiv d F
$$

then the dynamics of firm's assets is

$$
\frac{d V_{i}}{V_{i}}=\left(\mu_{v_{i}}-q_{V_{i}}\right) d t+B_{V_{i}} \sigma_{M} d M+u_{V_{i}} d \omega_{i}
$$

Therefore, the volatility of assets' returns per unit time is

$$
\sigma_{v_{i}}=\sqrt{B_{v_{i}}^{2} \sigma_{M}^{2}+u_{v_{i}}^{2}}
$$

the covariance between the assets' returns of $i$ and $j$ firms simplifies to

$$
B_{v_{i}} b_{v_{j}} \sigma_{M}^{2}
$$

and the asset correlation, $\rho_{i j}$, is equal to the product of the correlations with the market, $\rho_{\text {im }}$ and $\rho_{j M}$,

$$
\rho_{i j} \equiv \frac{\beta_{V_{i}} b_{V_{j}} \sigma_{M}^{2}}{\sigma_{V_{i}} \sigma_{V_{j}}}=\beta_{V_{i}} \frac{\sigma_{M}}{\sigma_{v_{i}}} \times b_{v_{j}} \frac{\sigma_{M}}{\sigma_{V_{j}}}=\rho_{i M} \times \rho_{j M}
$$

By dropping the subscript $i$, the dynamics of the assets of a generic firm is

$$
\frac{d V}{V}=\left(\mu_{V}-q_{V}\right) d t+B_{V} \sigma_{M} d M+u_{V} d \omega
$$

In other terms, we assume that the firm's assets follow a Geometric Brownian Motion

$$
\frac{d V}{V}=\left(\mu_{V}-q_{V}\right) d t+\sigma_{V} d z
$$

where the drift rate is

$$
\mu_{v}-q_{v}
$$

the variance rate, $\sigma_{V}^{2}$, is the sum of two (systematic, $\theta_{V}^{2} \sigma_{M}^{2}$, and idiosyncratic, $u_{V}^{2}$ ) components

$$
\sigma_{V}^{2}=B_{V}^{2} \sigma_{M}^{2}+u_{V}^{2}
$$

and $d z$ is a Wiener process

$$
d z \equiv \beta_{V} \frac{\sigma_{M}}{\sigma_{V}} d M+\frac{u_{V}}{\sigma_{V}} d \omega=\varepsilon \sqrt{d t}, \quad E(\varepsilon)=0 \quad \text { and } \quad E\left[(\varepsilon)^{2}\right]=\frac{B_{V}^{2} \sigma_{M}^{2}+u_{V}^{2}}{\sigma_{V}^{2}}=1
$$




\section{The optimal default trigger}

In our approach, debt is unprotected and the residual claimants (stockholders) have an option to default. They choose the bankruptcy level that maximize their wealth. ${ }^{5}$ The company defaults if the value of its assets drops below $V_{b}$, the optimal default trigger chosen by stockholders to maximize the value of equity: ${ }^{6}$

$$
V_{b}=Z \frac{\gamma}{\gamma-1}
$$

where

$$
v \equiv \frac{-\left(r-q_{V}-\sigma_{V}^{2} / 2\right)-\sqrt{\left(r-q_{V}-\sigma_{V}^{2} / 2\right)^{2}+2 \sigma_{V}^{2} r}}{\sigma_{V}^{2}}
$$

The value of the option to default

The current value, $P_{0}$, of the option to default is equal to: ${ }^{7}$

$$
P_{0}=\left(Z-V_{b}\right) p_{b}
$$

where $p_{b}$ is the current value of a perpetual first-touch digital option, written on $V$, that pays 1 when $V$ reaches $V_{b}\left(V_{0}>V_{b}\right)$

$$
p_{b}=\left(V_{0} / V_{b}\right)^{v}
$$

\section{The probability of default}

The probability of $V$ first hitting the barrier $V_{b}$ between time 0 and $T$ is

$$
Q(T)=N\left(-z_{1}\right)+\left(\frac{V_{0}}{V_{b}}\right)^{2(1-\lambda)} N\left(-z_{2}\right)
$$

where

$$
\begin{gathered}
z_{1}=\frac{\ln \left(V_{0} / V_{b}\right)+\left(r-q_{V}-\sigma_{V}^{2} / 2\right) T}{\sigma_{V} \sqrt{T}} \\
z_{2}=\frac{\ln \left(V_{0} / V_{b}\right)-\left(r-q_{V}-\sigma_{V}^{2} / 2\right) T}{\sigma_{V} \sqrt{T}} \\
\lambda=1+\frac{r-q_{V}-\sigma_{V}^{2} / 2}{\sigma_{V}^{2}}
\end{gathered}
$$

5 Jensen asks ([9], p. 218) "Is it the wealth of residual claimants, or bondholder wealth, or the combined wealth of bondholders and residual claimants that is to be maximized?". Since we wish to capture the basic structure of the firm, our answer is as simple as possible: It is the wealth of residual claimants that is to be maximized. In many circumstances equity holders do have the ability to choose when to default on debt and they will do it when it is optimal for them.

6 See Barone ([2], Equation (14), p. 359).

7 See Barone ([3]). 


\section{The dynamics of the option to default}

When $d V$ is given by Equation (34), the Merton's hedging argument shows that the price of any perpetual derivative whose value, $f$, depends on $V$ (but not on $t$ ), must satisfy the following fundamental differential equation:

$$
\frac{1}{2} \frac{d^{2} f}{d V^{2}} \sigma_{V}^{2} V^{2}+\left(r-q_{V}\right) V \frac{d f}{d V}-r f=0
$$

As shown in Barone [3], the delta and the gamma of the perpetual American put, in the continuation region (when $V>V_{b}$ ), are

$$
\begin{gathered}
\Delta_{P} \equiv \frac{d P}{d V}=\frac{\gamma P}{V} \\
\Gamma_{P} \equiv \frac{d^{2} P}{d V^{2}}=\frac{\gamma(\gamma-1) P}{V^{2}}
\end{gathered}
$$

By Itô's lemma, the dynamics of the option to default is

$$
d P=\left(\frac{d P}{d V}\left(r-q_{V}\right) V+\frac{1}{2} \frac{d^{2} P}{d V^{2}} \sigma_{V}^{2} V^{2}\right) d t+\frac{d P}{d V} \sigma_{V} V d z
$$

By substituting (46)-(47) in (49) and by taking into account that [Barone [3], Equation (8)]

$$
\frac{1}{2} \sigma_{v}^{2} \gamma(v-1)+\left(r-q_{V}\right) \nu-r=0
$$

we get

$$
\frac{d P}{P}=r d t+\gamma \sigma_{v} d z
$$

Therefore, the option to default follows a Geometric Brownian Motion with drift rate $r$ and variance rate $v^{2} \sigma_{v}^{2}$.

The dynamics of equity

Equity, the residual claim on firm's assets, is given by Equation (7)

$$
S_{0}=(1-\vartheta)\left(V_{0}-Z+P_{0}\right)
$$

where both $V_{0}$ and $P_{0}$ follow a Geometric Brownian Motion, while $\vartheta$ and $Z$ are constant.

The delta and the gamma of equity are

$$
\begin{aligned}
& \Delta_{S} \equiv \frac{d S}{d V}=(1-\vartheta)\left(1+\frac{\gamma P}{V}\right) \\
& \Gamma_{S} \equiv \frac{d^{2} S}{d V^{2}}=(1-\vartheta) \frac{\gamma(\gamma-1) P}{V^{2}}
\end{aligned}
$$

By Itô's lemma, the dynamics of equity is

$$
d S=\left(\frac{d S}{d V}\left(r-q_{V}\right) V+\frac{1}{2} \frac{d^{2} S}{d V^{2}} \sigma_{V}^{2} V^{2}\right) d t+\frac{d S}{d V} \sigma_{V} V d z
$$


Substituting (52)-(53) into (54) and taking (50) into account gives

$$
d S=(1-\vartheta)\left[r(V+P)-q_{V} V\right] d t+(1-\vartheta)(V+\gamma P) \sigma_{V} d z
$$

Besides, by (7) and (17), the drift is equal to

$$
\begin{aligned}
(1-\vartheta)\left[r(V+P)-q_{V} V\right] & =(1-\vartheta)\left[r(V-Z+P)-q_{V} V+r Z\right] \\
& =\left(r-q_{s}\right) s
\end{aligned}
$$

Therefore, substituting (56) in (55) gives the dynamics of equity as

$$
d S=\left(r-q_{S}\right) S d t+(1-\vartheta)(V+\gamma P) \sigma_{V} d z
$$

or, by (7) and (8), as

$$
\frac{d S}{S}=\left(r-q_{S}\right) d t+\sigma_{S} d z
$$

where the dividend yield, $q_{s}$, is

$$
q_{s}=\left(q_{V}-\frac{r Z}{V}\right) L
$$

and the equity volatility, $\sigma_{S}$, is

$$
\sigma_{S}=\left(1+v \frac{P}{V}\right) L \sigma_{V}
$$

Equation (58) collapses to a standard Geometric Brownian Motion in the case of a full-equity firm, where $P=0, L=1, q_{s}=q_{v}$ and $\sigma_{s}=\sigma_{V}$.

\section{THE DELEVERAGED CAPM}

As we already pointed out, we suppose that the instability of (CAPM) equity betas is due to leverage. The relationships between equity returns and the market factor is affected by stochastic changes of leverage. Therefore, it is unstable. In other terms, equity betas - differently from asset betas - cannot be assumed to be constant.

\section{Asset Betas}

By applying Itô's lemma to $(34)$, the $(0, T)$-period rate of return of assets per unit of time, $\eta_{V}$, is

$$
\eta_{V} \equiv \frac{\ln \left(V_{T} / V_{0}\right)}{T}=\left(r-q_{V}-1 / 2 \sigma_{V}^{2}\right) T+\sigma_{V} \sqrt{T} \varepsilon
$$

Therefore, as it is well known, the assumption of a Geometric Brownian Motion for the value of assets entails the "stable normality" of asset returns: The $(0, T)$-period logarithmic rates of return on assets are normal with constant mean $\left(r-q_{V}-1 / 2 \sigma_{V}^{2}\right) T$ and constant volatility $\sigma_{V} \sqrt{T}$.

By (37), Equation (61) can be written as

$$
\eta_{V} \equiv \frac{\ln \left(V_{T} / V_{0}\right)}{T}=\left(r-q_{V}-1 / 2 \sigma_{V}^{2}\right) T+B_{V} \sigma_{M} \sqrt{T} \varepsilon_{M}+u_{V} \sqrt{T} \varepsilon_{u}
$$

where $\varepsilon_{M}$ and $\varepsilon_{u}$ are two independent standardized normal variables.

The relationships (62) between asset returns, $\eta_{v}$, and the market portfolio, $M$, is linear and the asset beta, $b_{V}$, is constant. 


\section{Equity Betas}

By applying Itô's lemma to (58), the $(0, T)$-period rate of return of equity per unit of time, $\eta_{S}$, is,

$$
\eta_{S} \equiv \frac{\ln \left(S_{T} / S_{0}\right)}{T}=\left(r-q_{S}-1 / 2 \sigma_{S}^{2}\right) T+\sigma_{S} \sqrt{T} \varepsilon
$$

The fundamental difference between Equations (61) and (63) is that, while $q_{V}$ and $\sigma_{V}$ are constant, $q_{s}$ and $\sigma_{s}$ are stochastic, being both affected by the value of assets, $V$. In particular, as shown by (59)-(60), both $q_{s}$ and $\sigma_{s}$ are directly proportional to the firm's leverage, $L$.

This implies that the rates of return of equity are not "stably normal", i.e. they are not "normal with constant parameters". This is consistent with the leptokurtic ("heavy-tails") distributions of equity returns studied in the empirical literature.

This is also consistent with the typical downward-sloping volatility skew observed in options markets. In fact, one possible explanation for the volatility skew concerns leverage:

As a company's equity declines in value, the company's leverage increases. This means that the equity becomes more risky and its volatility increases. As a company's equity increases in value, leverage decreases. The equity then becomes less risky and its volatility decreases. This argument suggest that we can expect the volatility of a stock to be a decreasing function of the stock price ... (Hull [8], p. 437)

The equity volatility, $\sigma_{S}$, given by Equation (60), does change according to the above argument. By (37), Equation (63) can be written as

$$
\eta_{S} \equiv \frac{\ln \left(S_{T} / S_{0}\right)}{T}=\left(r-q_{S}-1 / 2 \sigma_{S}^{2}\right) T+B_{S} \sigma_{M}^{*} \sqrt{T} \varepsilon_{M}+u_{s}^{*} \sqrt{T} \varepsilon_{u}
$$

where the equity beta, $b_{S}$, the volatility of the "levered" market portfolio, $\sigma_{M}^{*}$, the residual volatility, $u_{s}^{*}$, and the leverage of the "levered" market portfolio, $L_{M}^{*}$, are

$$
B_{s}=\frac{B_{V}}{\sigma_{V}} \frac{\sigma_{M}}{\sigma_{M}^{*}} \sigma_{s} \quad u_{s}^{*}=\frac{u_{V}}{\sigma_{V}} \frac{u_{M}}{u_{M}^{*}} \sigma_{s} \quad L_{M}^{*}=\frac{\sigma_{M}^{*}}{\sigma_{M}}=\frac{u_{M}^{*}}{u_{M}}
$$

Therefore, the equity beta, $b_{s}$, is not constant, because, by $(60), \sigma_{s}$ is a function of $V$.

\section{SIMULATIONS}

Some simulations help to show the model's features.

\section{Asset Returns vs. Equity Returns: Density Functions}

First of all, we set the "environmental" parameters: the interest rate, $r=3 \%$, the tax rate, $\vartheta=$ $35 \%$, and the share of assets claimed by third parties when the firm defaults, $\alpha=20 \%{ }^{8} \mathrm{Be}-$ sides, suppose that the firm's parameters are equal to those typical of firms with ratings Aaa, Aa, A, Baa, Ba, B, Caa-C (Table 2). The density functions of asset returns and equity returns are shown in Figure 1 and Figure 2, respectively. Because of leverage, the equity returns are much more "disperse" than the asset returns (Please note the different vertical scales of the figures).

\footnotetext{
${ }^{8}$ In the years 2012-6, the average market yield on U.S. Treasuries at 30-year constant maturity has been equal to 3.03\% (U.S. Federal Reserve [15]). In the years 2014-6, the North America average of corporate tax rates has been equal to $33.25 \%$ (KPMG [10]). By using a sample of 175 firms that defaulted between 1997 and 2010, the mean cost of default for an average defaulting firm has been estimated to be equal to $21.7 \%$ (Davydenko, Strebulaev, and Zhao [5]).
} 
TABLE 2 Perpetual-Debt Structural Model: Estimates.

\begin{tabular}{|c|c|c|c|c|c|c|c|c|c|c|}
\hline \multirow{3}{*}{ Rating } & \multirow[b]{2}{*}{ Assets } & \multicolumn{4}{|c|}{ Liabilities } & \multirow[b]{2}{*}{$\begin{array}{l}\text { Business } \\
\text { Risk }\end{array}$} & \multirow{2}{*}{$\begin{array}{l}\text { Firm's } \\
\text { Leverage }\end{array}$} & \multirow{2}{*}{$\begin{array}{c}\text { Equity } \\
\text { Volatility }\end{array}$} & \multirow[b]{2}{*}{$\begin{array}{l}\text { Default } \\
\text { Point }\end{array}$} & \multirow[b]{2}{*}{$\begin{array}{c}\text { Recovery } \\
\text { Rate }\end{array}$} \\
\hline & & $\begin{array}{c}\text { Stock- } \\
\text { holders }\end{array}$ & $\begin{array}{c}\text { Bond- } \\
\text { holders }\end{array}$ & $\begin{array}{l}\text { Third } \\
\text { Parties }\end{array}$ & $\begin{array}{c}\text { Tax } \\
\text { Authority }\end{array}$ & & & & & \\
\hline & $V_{0}$ & $S_{0}$ & $B_{0}$ & $U_{0}$ & $G_{0}$ & $\sigma_{V}$ & $L$ & $\sigma_{S}$ & $V_{b}$ & $R$ \\
\hline Aaa & 198.22 & 64.22 & 64.33 & 0.29 & 69.38 & $10.61 \%$ & 2.01 & $21.05 \%$ & 79.65 & $63.72 \%$ \\
\hline $\mathrm{Aa}$ & 191.58 & 60.12 & 63.98 & 0.42 & 67.05 & $11.20 \%$ & 2.07 & $22.82 \%$ & 77.96 & $62.37 \%$ \\
\hline$A$ & 174.25 & 49.70 & 62.73 & 0.83 & 60.99 & $12.53 \%$ & 2.28 & $27.51 \%$ & 74.20 & $59.36 \%$ \\
\hline Baa & 151.60 & 36.23 & 60.93 & 1.38 & 53.06 & $13.32 \%$ & 2.72 & $33.70 \%$ & 71.99 & $57.59 \%$ \\
\hline $\mathrm{Ba}$ & 116.63 & 19.51 & 53.43 & 2.87 & 40.82 & $16.97 \%$ & 3.89 & $53.43 \%$ & 62.29 & $49.83 \%$ \\
\hline B & 86.66 & 13.55 & 39.53 & 3.24 & 30.33 & $26.58 \%$ & 4.16 & $78.68 \%$ & 42.19 & $33.75 \%$ \\
\hline Caa-C & 56.53 & 5.03 & 28.39 & 3.33 & 19.79 & $32.67 \%$ & 7.31 & $130.76 \%$ & 33.32 & $26.66 \%$ \\
\hline
\end{tabular}

Note: $Z=100, r=3 \%, q_{V}=1 \%, \vartheta=35 \%, \alpha=20 \%$. Source: Barone [4], Table 2, p. 6

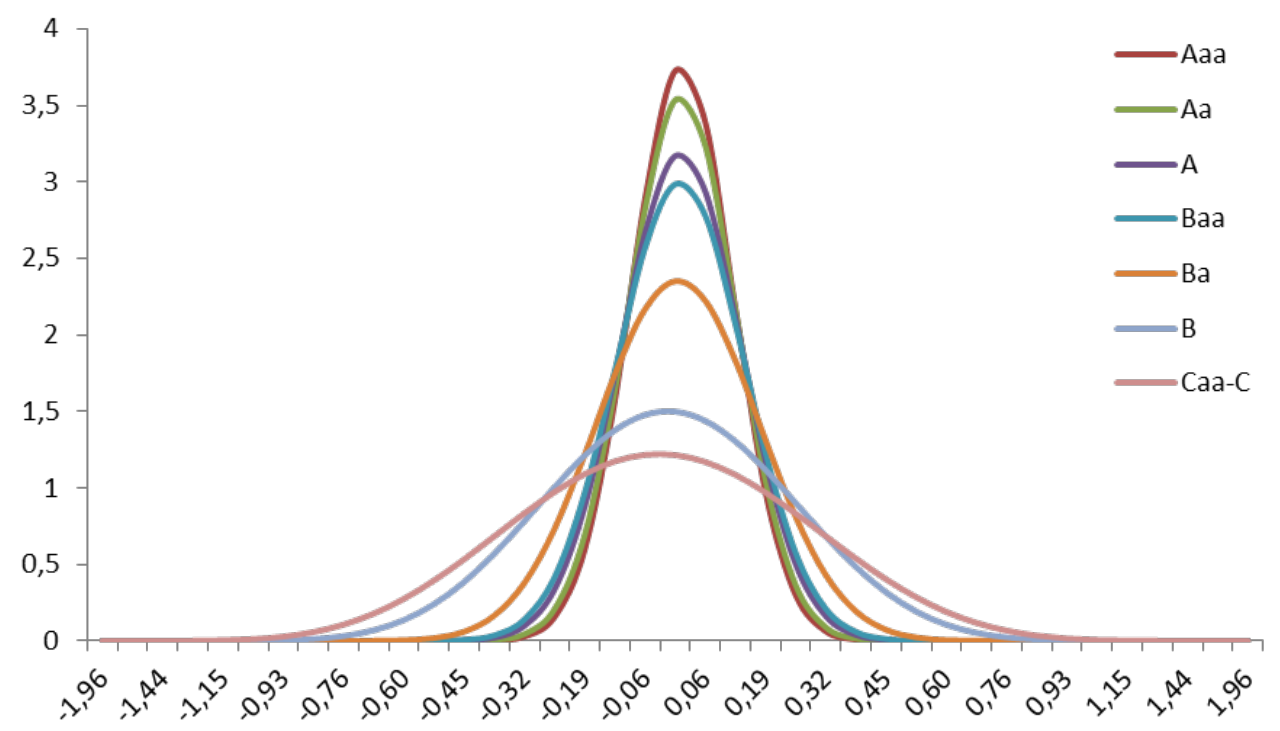

Figure 1 Distribution of Asset Returns by Rating's Class.

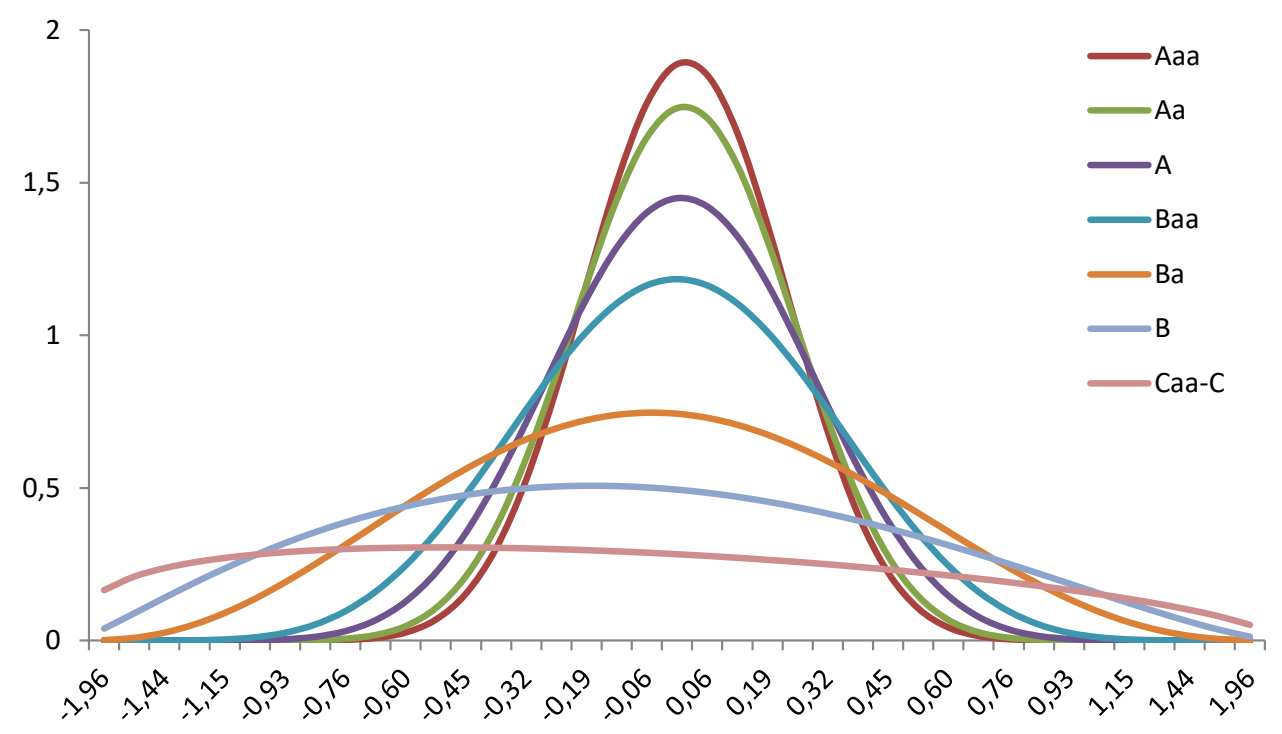

Figure 2 Distribution of Equity Returns by Rating's Class. 


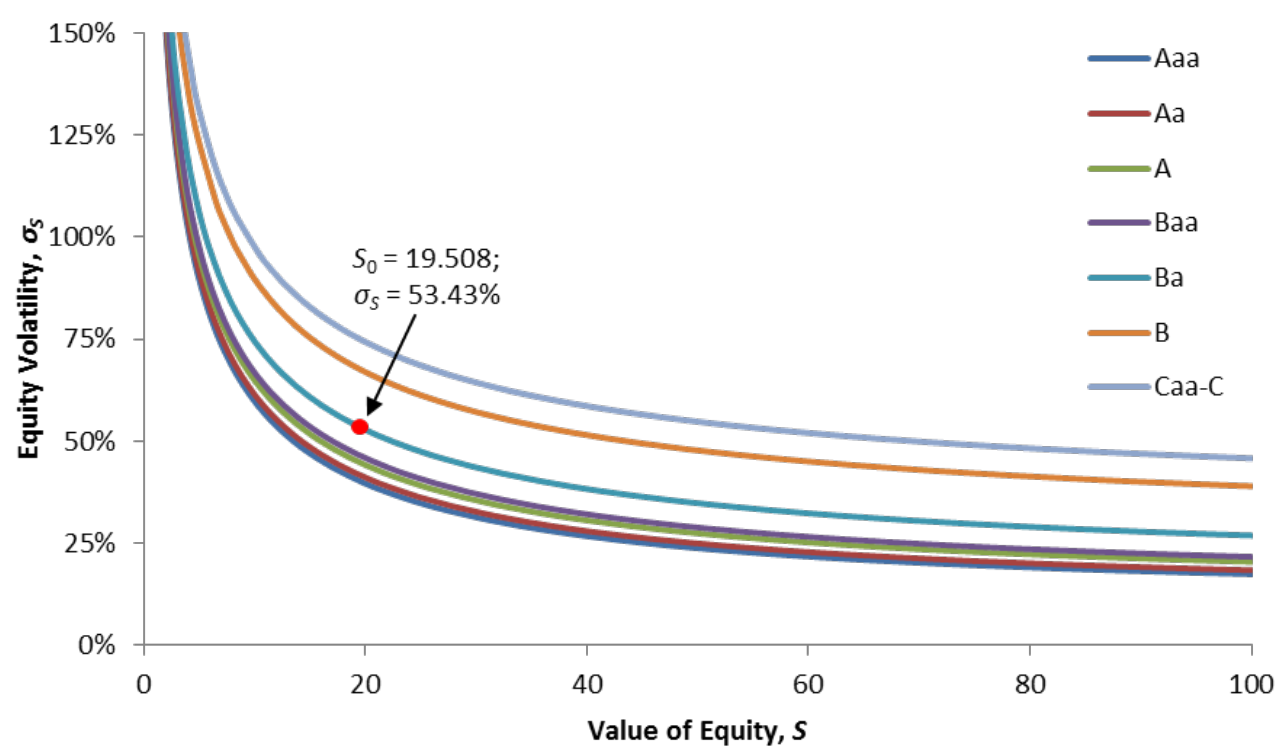

Figure 3 Equity Volatility as a Function of the Value of Equity.

TABLE 3 Asset Betas by Rating's Class.

\begin{tabular}{cccc}
\hline \multirow{2}{*}{ Rating } & $\begin{array}{c}\text { Asset } \\
\text { Beta }\end{array}$ & $\begin{array}{c}\text { Idiosyncratic } \\
\text { Volatility }\end{array}$ & $\begin{array}{c}\text { Business } \\
\text { Risk }\end{array}$ \\
\cline { 2 - 4 } & $B_{V}$ & $u_{V}$ & $\sigma_{V}$ \\
\hline Aaa & 0.797 & $7.50 \%$ & $10.61 \%$ \\
Aa & 0.841 & $7.92 \%$ & $11.20 \%$ \\
A & 0.941 & $8.86 \%$ & $12.53 \%$ \\
Baa & 1.000 & $9.42 \%$ & $13.32 \%$ \\
Ba & 1.274 & $12.00 \%$ & $16.97 \%$ \\
B & 1.996 & $18.80 \%$ & $26.58 \%$ \\
Caa-C & 2.453 & $23.10 \%$ & $32.67 \%$ \\
\hline
\end{tabular}

Note: $Z=100, r=3 \%, q_{V}=1 \%, \vartheta=35 \%, \alpha=20 \%, \sigma_{M}=9.42 \%$.

\section{Equity Volatility}

Consider a Ba firm with $V_{0}=116.63, Z=100, q_{V}=1 \%, \sigma_{V}=16.97 \%$ (Table 2). By (38)-(41), $v=$ $-1.652, V_{b}=62.29, p_{b}=0.3549, P_{0}=13.383$ and, by (7)-(8), $S_{0}=19.508, L_{0}=3.886$.

Equity volatility is given by Equation (60). It turns out that $\sigma_{S}=53.43 \%$ if $V_{0}=116.63$. Figure 3 shows the equity volatility, as a function of $S$, for all the rating's classes that we have considered. Notice that $\sigma_{S} \rightarrow+\infty$ as $V \rightarrow V_{b}(S \rightarrow 0)$ and $\sigma_{S} \rightarrow \sigma_{V}$ as $V \rightarrow+\infty(S \rightarrow+\infty)$.

\section{Asset Betas}

Now suppose that the market portfolio has a volatility, $\sigma_{M}$, equal to $9.42 \% .{ }^{9}$ Table 3 shows the asset volatility's breakdown into its systematic and idiosyncratic components, for given values of asset betas, $B_{V}$. By construction, Aaa-Aa-A firms are defensive, Baa firms are market-neutral, and $\mathrm{Ba}-\mathrm{B}-\mathrm{Caa}-\mathrm{C}$ firms are aggressive.

9 The values of market volatility, $\sigma_{M}$, and asset betas, $b_{V}$, have been chosen in order to make (i) the systematic component, $B_{V}^{2} \sigma_{M}^{2}$, equal to the $50 \%$ of the variance rate, $\sigma_{V}^{2}$, and (ii) $B_{V}=1$ for the Baa firm. Therefore, by (29), all the pairwise correlations are equal to 0.5 . 


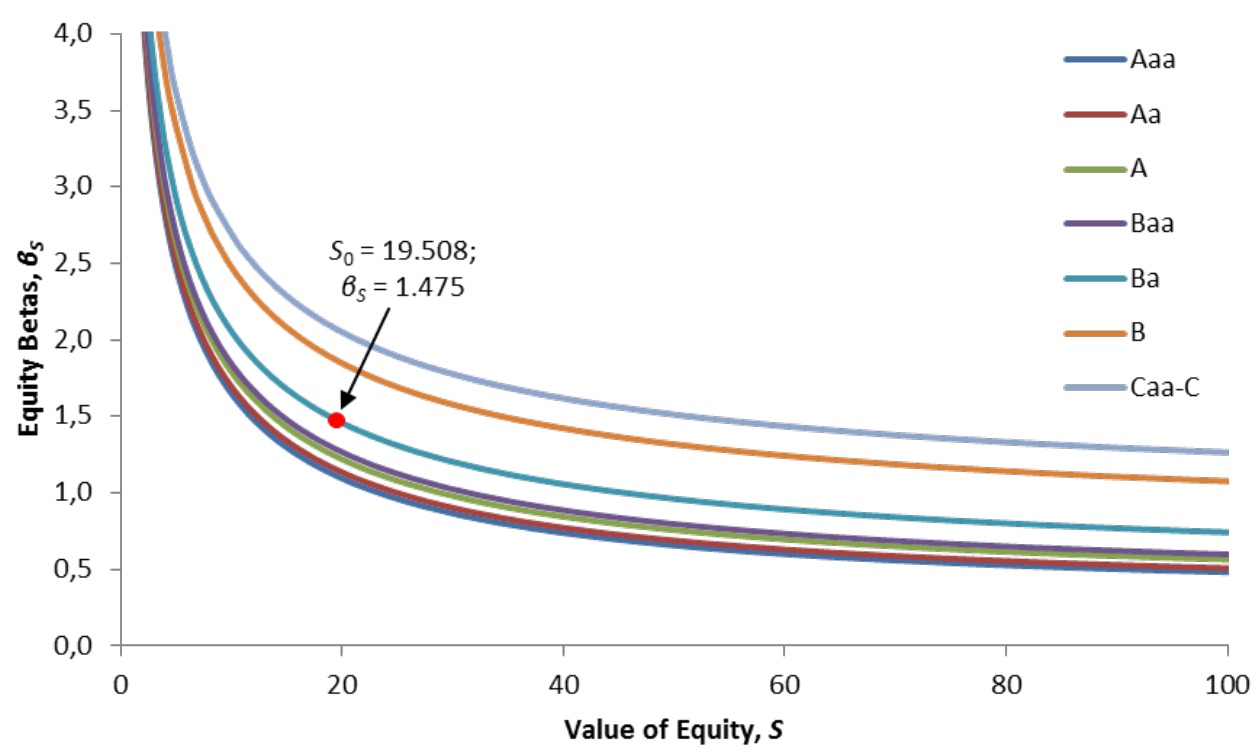

Figure 4 Equity Betas as a Function of the Value of Assets.

\section{Equity Betas}

Equity betas are defined by (65). They are a negative non-linear function of the value of equity (Figure 4). ${ }^{10}$

\section{CONCLUSIONS}

The instability of the estimates of "classical" equity betas have relevant effects on asset management because it makes unreliable the vector of expected returns and the variancecovariance matrix for portfolio selection. We have shown that a possible cause of instability is represented by firms' leverage, that stochastically changes over time.

In order to overcome the instability's problem, asset managers can follow a three-step approach:

1. to estimate the (unobserved) market value of firm's assets, $V$, the debt's nominal value, $Z$, the payout rate, $q_{v}$, the business risk, $\sigma_{v}$, by using market data on the value of equity, $S$, the dividend yield, $q_{S}$, the volatility of equity, $\sigma_{S}$, and estimates of "environmental" parameters (the interest rate, $r$, the tax rate, $\vartheta$, the share of assets claimed by third parties when the firm defaults, $\alpha$ );

2. to estimate the (unobserved) "unlevered" market portfolio;

3. to estimate the asset betas of the linear relationships between the asset returns and the "unlevered" market returns.

Companion papers will show how to implement the above approach.

10 Figure 4 has been built under the hypothesis that the leverage of the "levered" market portfolio, $L_{M}^{*}$, is equal to 2.72 , the leverage of the market-neutral firm with rating Baa. 


\section{REFERENCES}

[1] Authers, J., "Is 'smart beta' smart enough to last?", Financial Times, June 11, 2014.

[2] Barone, G., "An Equity-Based Credit Risk Model", in Jonathan A. Batten and Niklas Wagner (Eds.), Derivative Securities Pricing and Modelling. Bingley, UK: Emerald, vol. 94, pp. 351378, July 2012.

[3] Barone, G., "European Compound Options Written on Perpetual American Options", Journal of Derivatives, Spring 2013, Vol. 21, No. 1, pp. 61-74.

[4] Barone, G., "Mimicking Credit Ratings by a Perpetual-Debt Structural Model", April 2016 (see SSRN-id2714296.pdf)

[5] Davydenko, S. A., Strebulaev, I. A., and Zhao, X., "A Market-Based Study of the Cost of Default", Review of Financial Studies, Vol. 25, no. 10, pp. 2959-99, 2012.

[6] FARFE, "Citation for the First Ross Prize", http://farfe.org/ross_prize-2008.html, December $9,2008$.

[7] Granger, C. W. J., and Morgenstern, O., Predictability of Stock Market Prices, Heath Lexington, 1970.

[8] Hull, John C., Options, Futures, and Other Derivatives, 9th ed., Pearson, 2015.

[9] Jensen, M. C., "A Theory of the Firm - Governance, Residual Claims, and Organizational Forms", Harvard University Press, 2000.

[10] KPMG, "Corporate Tax Rates Table", home.kpmg.com/.../corporate-tax-rates-table.html, 2016.

[11] Kahn, R.N., and Lemmon, M., “The Asset Manager's Dilemma: How Smart Beta Is Disrupting the Investment Management Industry", Financial Analysts Journal, Vol. 72, no. 1, pp. 15-20, 2016.

[12] Leland, H., "Corporate Debt Value, Bond Covenants, and Optimal Capital Structure", Journal of Finance, 49 (4), pp. 1213-52, September 1994.

[13] Ross, S. A., "The Arbitrage Theory of Capital Asset Pricing", Journal of Economic Theory, vol. 13, pp. 341-60, 1976.

[14] Rubinstein, Mark, A History of the Theory of Investment - My Annotated Bibliography, Hoboken, NJ: John Wiley \& Sons, pp. 1-370, 2006.

[15] U.S. Federal Reserve, "Selected Interest Rates", www.federalreserve.gov, 2016. 